Brit. Heart F., 1967, 29, 594.

\title{
Jamaican Cardiomyopathy
}

\author{
KENNETH R. HILL, W. J. S. STILL^, AND BRIAN MCKINNEY† \\ From the Department of Pathology, Royal Free Hospital School of Medicine, London W.C.1
}

There have been numerous reports relating to cardiac failure due to cardiomyopathies of unknown ætiology. Although a few cases of this type of cardiomyopathy have been reported from Europe (Mumme, 1940; Edge, 1946; Lynch and Watt, 1957; Penfold, 1957) and North America (Smith and Furth, 1943; McNicol et al., 1953; Dyson and Decker, 1958), by far the highest incidence appears to be in certain African centres (Davies and Ball, 1955) and to a lesser extent in South America (Correa et al., 1963) and the Caribbean (Stuart and Hayes, 1963).

The best known of these obscure cardiomyopathies is probably endomyocardial fibrosis which was first described by Bedford and Konstam (1946). These workers encountered it amongst West African troops serving in the Sudan. It has been reported from other parts of Africa and has been shown to have a particularly high incidence in Uganda (Davies, 1948), the Sudan (O'Brien, 1954), and Nigeria (Edington and Jackson, 1963), but has also been described in Brazil (Andrade and Guimarãis, 1964), and Ceylon (Nagaratnam and Dissanayake, 1959). It affects the indigenous populations of these regions almost exclusively but cases have been reported amongst Europeans who have been resident in these countries for many years (Gray, 1951).

The condition is characterized by diffuse or plaque-like endocardial thickening in one or both ventricles, with or without mural thrombosis, and with a varying degree of myocardial hypertrophy. In addition, it is common to find some evidence of myocardial fibrosis, which, in most cases, is confined to the inner third of the affected ventricle. In some cases, particularly those from Uganda, valvular stenosis may occur.

Descriptions of other obscure types of heart disease have come from widely separated areas of

Received September 29, 1966.

* Present address: Department of Pathology, Medical College of Virginia, Richmond, Virginia, U.S.A.

tWellcome Trust Research Fellow. the tropics and include two varieties from South Africa, namely nutritional heart disease (Gillanders, 1951) and cardiovascular collagenosis (Becker, Chatgidakis, and van Lingen, 1953), and heart muscle disease from Nigeria (Edington and Jackson, 1963), and unnamed cardiomy'opathies from Cali, Columbia (Correa et al., 1963) and Jamaica (Stuart and Hayes, 1963).

The ætiology of all these conditions is unknown. Two hypotheses have, so far, been put forward as to the origin of endomyocardial fibrosis, first that it is of an infectious origin (Parry and Abrahams, 1965) and secondly that its ætiology is due to a high dietary intake of plantains (McKinney and Crawford, 1965).

The geographical origin, as so far recorded, appears to be of some significance and, for this reason, the following account from Jamaica, West Indies, is presented.

\section{Pathology}

Seven examples of this cardiomyopathy were found in 400 consecutive necropsies at University College Hospital, Kingston, Jamaica, together with a single case from another hospital. There were six men and two women, and the ages ranged from 19 to 60 years. In three cases coincidental diseases were also found: pulmonary tuberculosis in two and acute falciparum malaria in one, while the youngest of the series died following a cæsarean section. The heart weights ranged from 480 to $275 \mathrm{~g}$., seven of the hearts weighing more than $370 \mathrm{~g}$.

The distribution of the macroscopic endocardial thickening was as follows. In seven it was confined to the left side of the heart, particularly conspicuous in the left ventricle but also present in the atrium. In one case only was the right ventricular endocardium involved. Emphasis has been placed on ventricular, rather than atrial, thickening since the latter is much harder to assess, even histologic594 


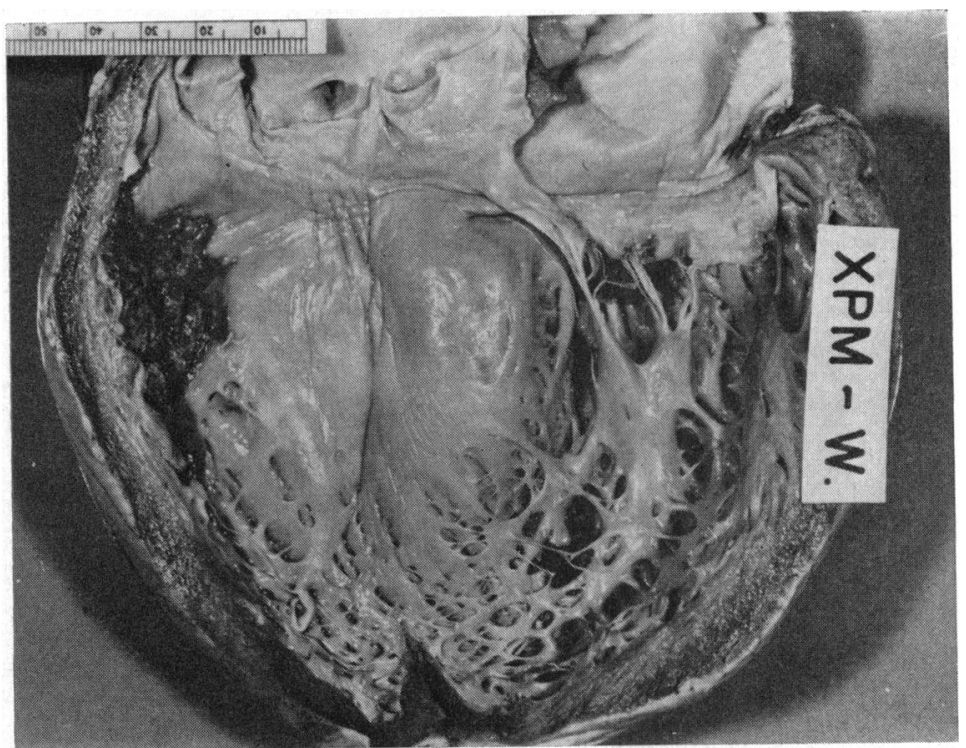

FIG. 1.-Left ventricle: the endocardium is diffusely thickened, and organizing mural thrombi are present. The valves are normal.

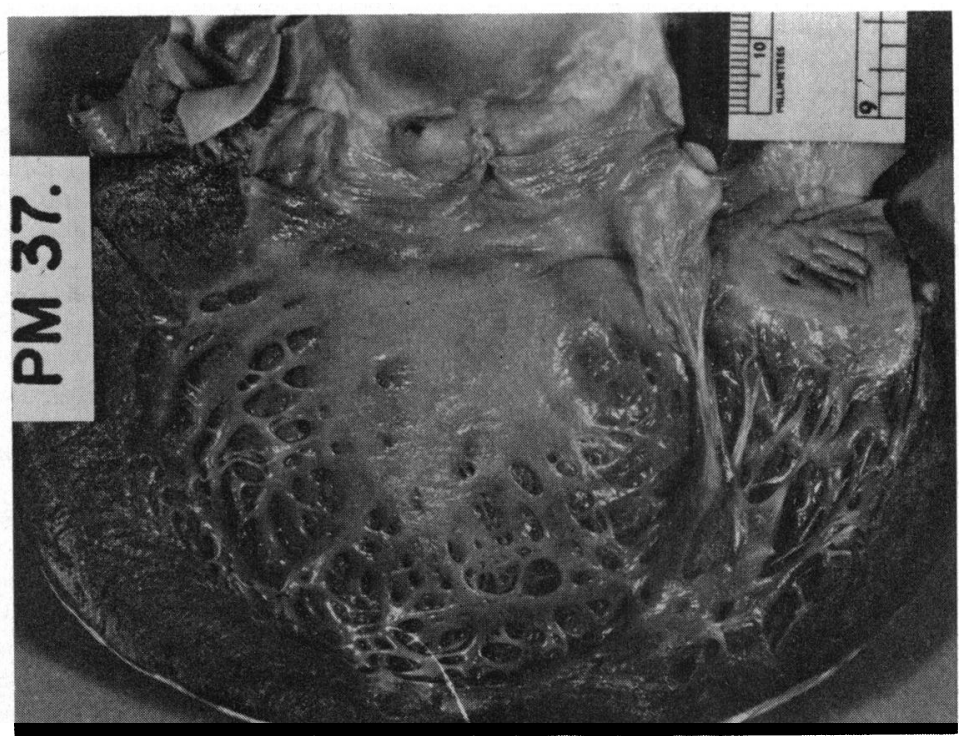

Fig. 2.-Left ventricle: a dilated chamber with a moderate degree of diffuse endocardial thickening.

in the left ventricle, and two of these cases also showed systemic emboli from this source. In only three cases was any valvular involvement evident: the mitral valve in two, and the aortic valve in one. In none of these cases was the involvement severe.

The ,endocardial thickening was diffuse in all instances, showing no greater thickening in one area of the ventricle than another (Fig. 1 and 2). The degree of thickening was considered to be severe in two cases, moderate in four, and mild in two. No lesions of any significance were found in the main trunks or the larger branches of the coronary vessels. 


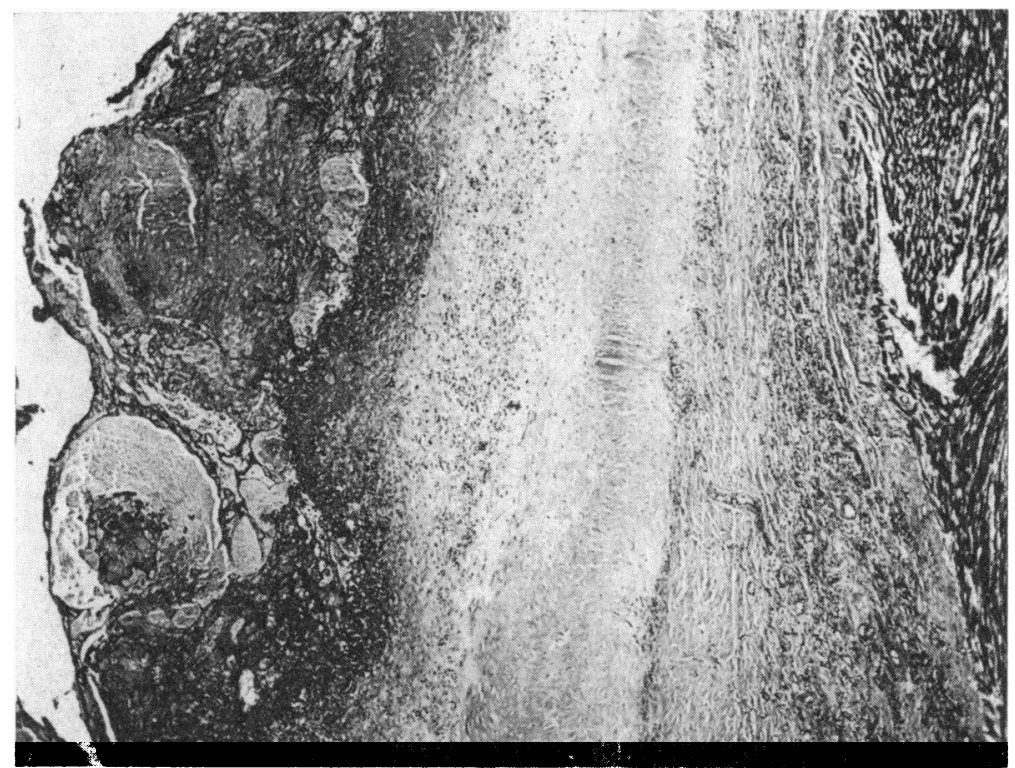

Fig. 3. - Section taken from an area of mural thrombosis in Fig. 1. The three fairly distinct layers are shown. (H. and E. $\times$ 100.)

\section{HistologY}

The histological appearances of the endocardium and myocardium are, in many ways, similar to those described in Uganda (Davies and Ball, 1955), though nearly always less severe. Where there is a mural thrombus, the endocardium shows three fairly distinct layers (Fig. 3): innermost the organizing thrombus, then a layer of relatively acellular compressed hyaline material, and between this and the myocardium a layer of cellular connective tissue containing many thin-walled blood spaces and vessels, the so-called "granulation" tissue zone of Davies and Ball. In other areas where mural thrombosis is not obvious, remains of this, or fibrin deposition, can still be seen embedded in the superficial parts of the hyaline layer (Fig. 4).

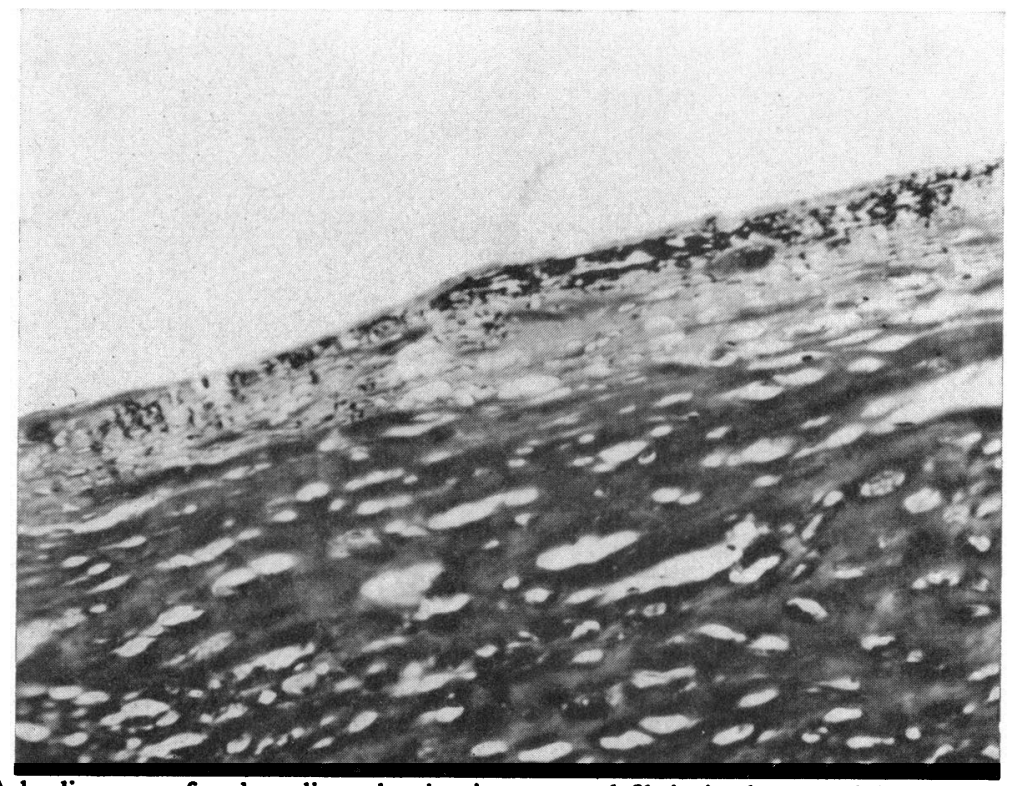

FIG. 4.-A hyaline area of endocardium showing incorporated fibrin in the superficial zones. (P.T.A.H. $\times 200$.) 


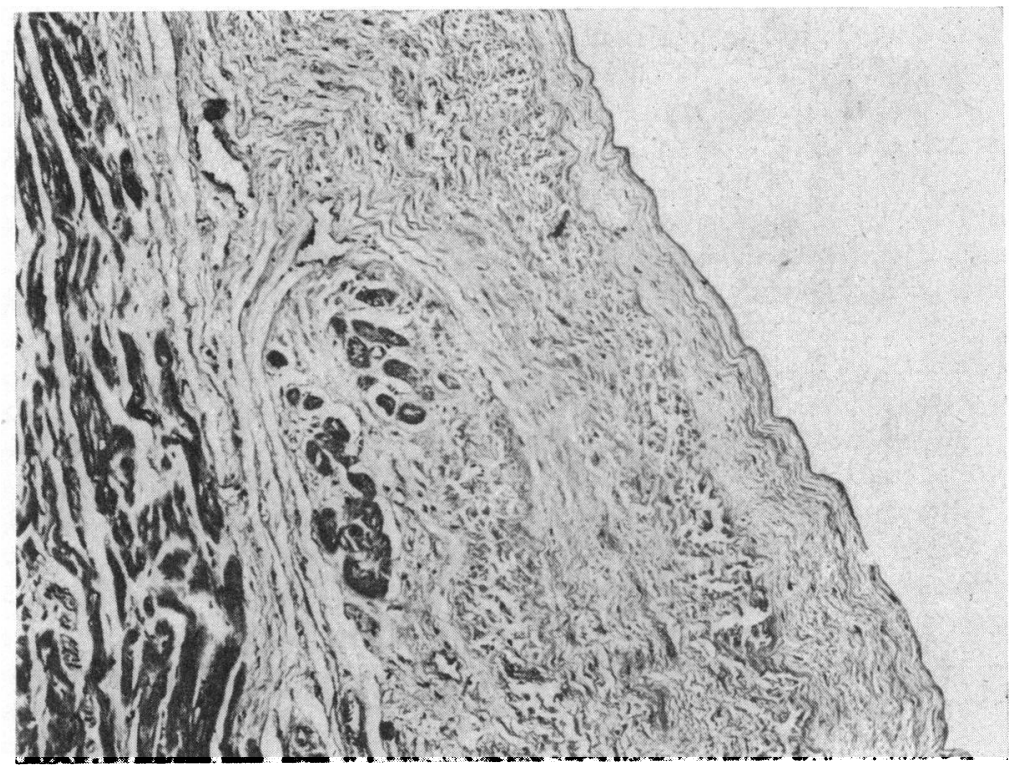

FIG. 5.-A more compact area of endocardium with subendocardial fibrosis. (H. and E. $\times 150$.)

Over quite large areas, the endocardium shows no evidence of mural fibrin deposition, and the thickening consists of either hyaline material as seen in Fig. 3, with little or no evidence of a granulation tissue zone, or more cellular, compact, connective tissue (Fig. 5). The latter areas appear to be much more conspicuous here than in cases of endomyocardial fibrosis, especially as described by Davies in Uganda. These appearances, particularly the second, pose the question whether the endocardial thickening generally is due to previous mural deposition and subsequent organization, or whether the deposition is a phenomenon on an already thickened endocardium.

The hyaline areas present little problem, since careful search will reveal evidence of fibrin deposits on the endocardial surfaces. With regard to cases of more cellular thickening, it has been shown (Still and Boult, 1956, 1957) that if the endocardium in endocardial fibro-elastosis is examined by electron microscopy, fibrin-like material is found in the superficial layers though histologically it cannot be demonstrated. Similarly, when these hyaline and collagenous areas of endocardial thickening are examined by electron microscopy, it becomes clear that the superficial areas do in fact contain material which closely resembles fibrin (Fig. 6). This fibrinlike material is seen also in the superficial areas of the rugose white thickened areas of the Uganda hearts (W. J. S. Still, unpublished observation). Fibrin can also be demonstrated in these areas by the use of fluorescent anti-fibrin serum (B McKinney, personal observation, 1966).

The elastic tissue content of the endocardium varies widely: in some areas it is scanty or not apparently present; in others the hyaline layers are sprinkled with short fibrillary lengths of material taking elastic tissue stains (Fig. 7). It is exceptional to find well-organized elastic tissue hyperplasia. The areas where such hyperplasia is found are usually those showing a comparatively minor degree of compact thickening (Fig. 8). The most likely explanation for this is that these are areas showing thickening of longer duration where elastic tissue formation, always a slow process, is more advanced.

The degree of myocardial damage also varies. There may be conspicuous fibrosis of the inner third of the ventricular wall, or more typically, the fibrosis may be confined to the subendocardial zone (Fig. 9). In contrast, some areas show only minimal degenerative changes in the subendocardial fibres with no evident fibrosis. In general, the greatest myocardial damage relates to the greater degrees of endocardial thickening, but this is by no means an absolute rule.

No lesions of apparent significance were found in the main coronary vessels, and there was no indication that the blood flow was inadequate. The smaller coronary radicles showed on occasion some eccentric intimal thickening, but this was not a consistent or widespread finding. Such intimal thick- 


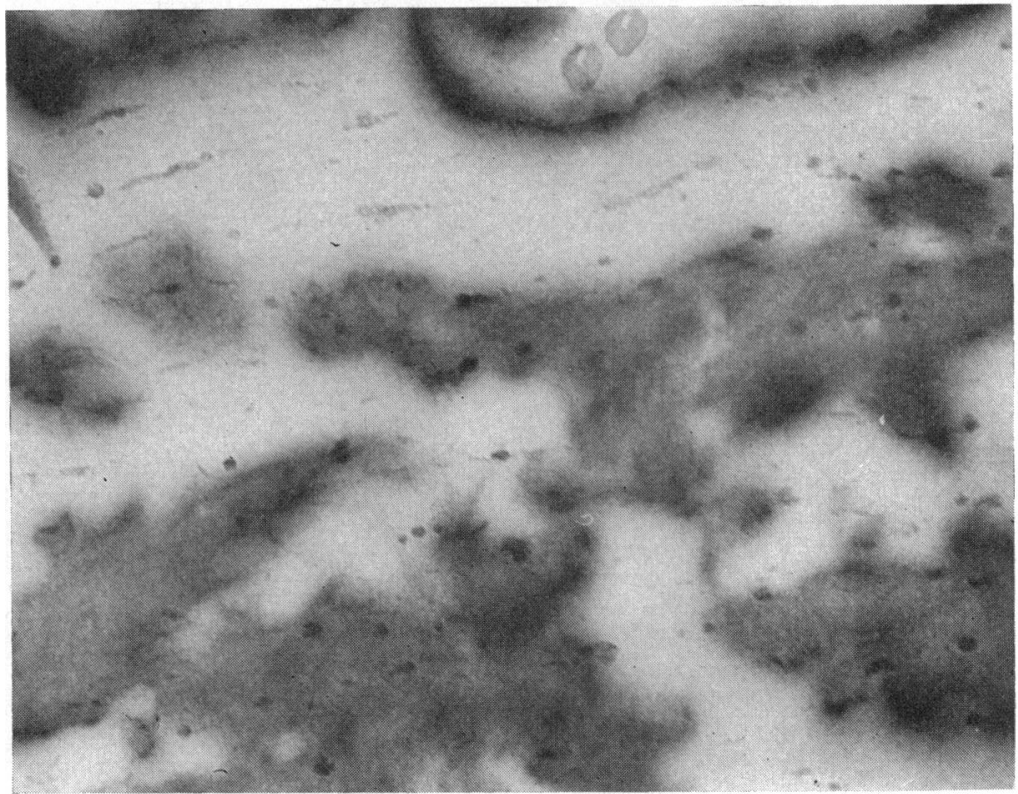

FIG. 6.-An electron microscopic thin section of the surface zone of an area of compact endocardium. Part of an endothelial cell is seen above. Deep to this is a fibrillary mass of fibrin. $(\times 24,000$.

ening in small blood vessels was reported in examples of the South African cardiomyopathy described by Becker (1963).

\section{Discussion}

The Jamaican cardiomyopathy, as described above, can be distinguished from endomyocardial fibrosis reported from other parts of the world, particularly Africa, first, by the fact that the heart is appreciably larger than that found in typical endomyocardial fibrosis, as described by Davies in Uganda; secondly, that little valvular involvement is present; thirdly, that the endocardial lesions are not confined to the inflow tracts; and fourthly, that

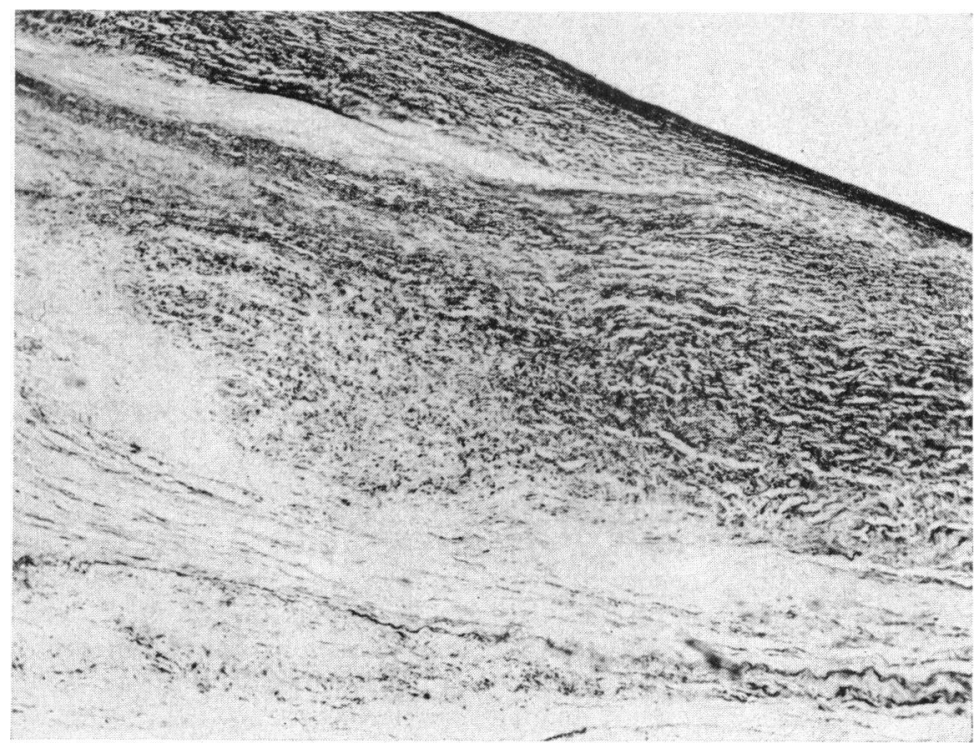

FIG. 7.-Fragmentary elastic tissue formation in an area of fairly severe thickening. (Weigert's elastica $\times 150$.) 


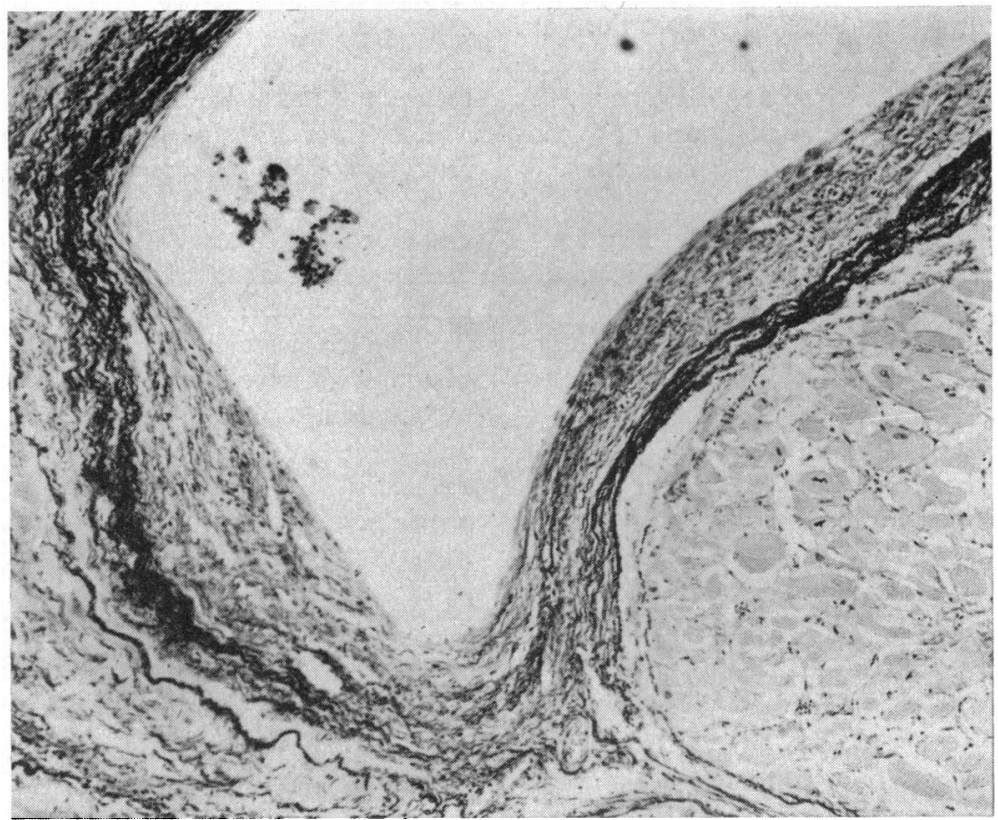

FIG. 8.-Well-marked elastic tissue hyperplasia in a compact area of endocardium. Note that the more recently formed tissue shows little elastic tissue. (Weigert's elastica $\times 150$.)

the endocardial fibrosis diffusely involves all the endocardium of ventricle and atrium, most usually on the left side. Moreover, there is no myocytolysis, an essential change in endomyocardial fibrosis
(D. A. Conor, 1965, personal communication).

The histological appearances are in many respects similar, though the processes appear more florid in endomyocardial fibrosis as described by Davies in

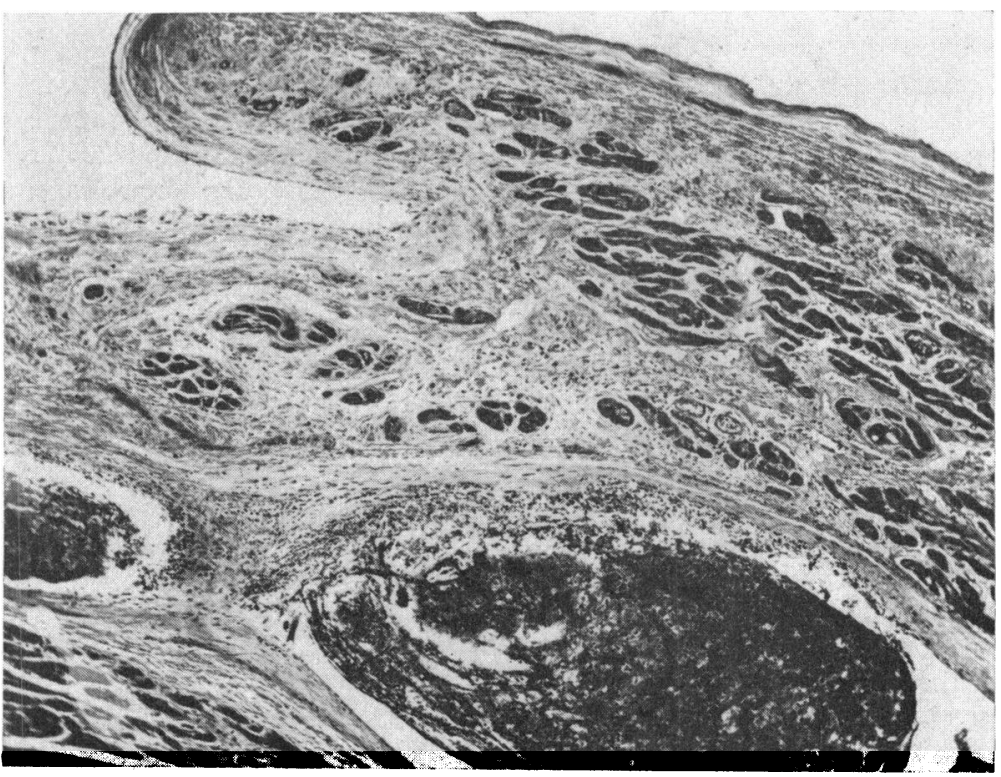

FIG. 9.-An area showing considerable subendocardial fibrosis, with organizing thrombi present in the trabeculæ. (H. and E. $\times$ 100.) 
Uganda. Whether this and the other variations are a matter of degree, or signify some absolute difference, is uncertain, and the same doubt exists on the relationships between the various groups of "idiopathic" endocardial fibrosis reported elsewhere.

There can be little doubt that the organization of mural thrombi, and more particularly fibrin deposits, is a major factor in the development of this endocardial thickening. Fibrin remnants can be found even in the most hyaline areas of the endocardium, and electron microscope studies can trace the same process in areas where all histological evidence has either disappeared or where the deposition process is too fine to be shown by conventional methods. Dyson and Decker (1958), seeing these same appearances in a series of North American patients, have commented on their similarity to the processes portrayed by Duguid $(1946,1948)$ in his description of the thrombotic origin of arterial atherosclerosis. These workers contend that the endocardial condition is similar in production and modified in its details by the organ involved.

In Uganda and Nigeria, so-called "heart muscle" disease, which these hearts more closely resemble, has been described (Edington and Jackson, 1963), as also from Brazil (Andrade and Guimarãis, 1964). In "heart muscle" disease or in the South African cardiomyopathies, the hearts are usually enlarged and dilated, and fibrosis occurs over all the endocardium, though most commonly on the left side and not involving the valves as in endomyocardial fibrosis. Davies and Hollman (1965) have reported one case of Becker's disease in London in a negro girl from Barbados, but this does not demonstrate that the Jamaican cases are comparable.

This description does not provide any information on the pathogenesis which has already been discussed by many workers (Williams, Ball, and Davies, 1954; Dyson and Decker, 1958); but it does lend support to the supposition that a diet consisting largely of plantains may be responsible for the occurrence of many of the cardiomyopathies in which endocardial fibrosis is seen, as bananas and plantains form a large part of the dietary intake of many Jamaicans (J. A. Hayes, 1965, personal communication), as they do in many other areas where these cardiomyopathies are seen, e.g. Columbia (C. Garcia, 1965, personal communication), and Uganda (B.McKinney, 1963, personal observation). A geographical distribution of disease has been looked for in Jamaica but this has not been found as cases appear to be scattered widely throughout the island (W. E. Miall, 1965, personal communication). This cannot be significant as plantains and bananas grow and are eaten all over the island.

The first question is whether we are dealing in all cases with a disease process involving the endocardium or one that involves the myocardium, with secondary involvement of the endocardium giving rise to thickening as a later event. Probably the majority of workers favour the latter hypothesis. Thus, the experimental work of McKinney and Crawford (1965) showed that the earliest change in the hearts of their experimental animals was the presence of acid mucopolysaccharides in some of the myocardial cells immediately below the endocardium, followed by a hyaline change of all the myocardial fibres lying below the endocardium, and only then by hyperplasia and latterly by fibrous thickening of the endocardium overlying some areas of the myocardium. Their finding is in agreement with that of Evans (1949) in familial cardiomyopathies in England, but its significance is not clear.

It must be borne in mind, however, that the myocardial fibres immediately below the endocardium receive blood from the ventricular cavity through the endocardium. Any endocardial thickening will interfere with this blood supply, and therefore it is not necessary to postulate a myocardial disease to explain any fibrin in the underlying muscle.

\section{SUMMARY}

Eight cases of a cardiomyopathy found in Jamaica are described. The ages ranged from 19 to 60 years. There were six men and two women. All the hearts were enlarged, the weights ranging from 480 $370 \mathrm{~g}$., except for one patient in whom the heart weighed $275 \mathrm{~g}$.

The principal pathological finding was fibrous thickening of the endocardium confined to the left side in seven patients and most evident in the ventricles. Four hearts showed mural thrombi which in two instances had given rise to systemic emboli. Valvular involvement-slight-was seen in only three patients.

The endocardial thickenings contained deposits of fibrin and originated from them.

This cardiomyopathy resembles most closely "heart muscle" disease as found in Nigeria.

We wish to thank Professor J. B. Duguid for his help in initiating this investigation; Dr. D. C. Watt from the Kingston Public Hospital for allowing us to study one of his cases; and Professor J. N. P. Davies for kindly supplying specimens of East African endomyocardial fibrosis.

\section{REFERENCES}

Andrade, Z. A., and Guimarãis, A. C. (1964). Endomyocardial fibrosis in Bahia, Brazil. Brit. Heart f., 26, 813. 
Becker, B. J. P. (1963). Idiopathic mural endocardial disease in South Africa. Med. Proc., 9, 124 and 147.

-, Chatgidakis, C. B., and van Lingen, B. (1953). Cardiovascular collagenosis with parietal endocardial thrombosis. Circulation, 7, 345.

Bedford, D. E., and Konstam, G. L. S. (1946). Heart failure of unknown ætiology in Africans. Brit. Heart f., 8, 236.

Correa, P., Restrepo, C., García, C., and Quiroz, A. C. (1963). Pathology of heart diseases of undetermined etiology which occur in Cali, Colombia. Amer. Heart f., 66, 584.

Davies, J. N. P. (1948). Pathology of central African natives. Mulago Hospital post mortem studies. IX. Cardio-vascular diseases. E. Afr. med. F., 25, 454.

- , and Ball, J. D. (1955). The pathology of endomyocardial fibrosis in Uganda. Brit. Heart f., 17, 337.

- , and Hollman, A. (1965). Becker type cardiomyopathy in a West Indian woman. Amer. Heart f., 70, 225.

Duguid, J. B. (1946). Thrombosis as a factor in the pathogenesis of coronary atherosclerosis. F. Path. Bact., 58, 207.

- (1948). Thrombosis as a factor in the pathogenesis of aortic atherosclerosis. F. Path. Bact., 60, 57.

Dyson, B. C., and Decker, J. P. (1958). Endocardial fibroelastosis in the adult. Arch. Path., 66, 190.

Edge, J. R. (1946). Myocardial fibrosis following arsenical therapy. Lancet, 2, 675.

Edington, G. M., and Jackson, J. G. (1963). The pathology of heart muscle disease and endomyocardial fibrosis in Nigeria. F. Path. Bact., 86, 333.

Evans, W. (1949). Familial cardiomegaly. Brit. Heart f., 11, 68.

Gillanders, A. D. (1951). Nutritional heart disease. Brit. Heart F., 13, 177.

Gray, I. R. (1951). Endocardial fibrosis. Brit. Heart f., 13, 387.
Lynch, J. B., and Watt, J. (1957). Diffuse endomyocardial sclerosis. Brit. Heart f., 19, 173.

McKinney, B., and Crawford, M. A. (1965). Fibrosis in guineapig heart produced by plantain diet. Lancet, 2, 880.

McNicol, C., MacMahon, H. E., Benenson, A. S., and Winship, T. (1953). Recurrent parietal thromboendocarditis. Circulation, 7, 497.

Mumme, C. (1940). Zur Klinik und Pathologie der Endokarditis und Aortitis fibroplastica sowie Thromboendarteriitis obliterans mit hochgradiger Eosinophilie im Blut, Knochenmark und in den Organen. Z.Klin. Med., 138, 22.

Nagaratnam, N., and Dissanayake, R. V. P. (1959). Endomyocardial fibrosis in the Ceylonese. Brit. Heart f., 21, 167.

O'Brien, W. (1954). Endocardial fibrosis in the Sudan. Brit. med. F., 2, 899.

Parry, E. H. O., and Abrahams, D. G. (1965). The natural history of endomyocardial fibrosis. Quart. F. Med., 34, 383.

Penfold, J. B. (1957). Endocardial fibrosis of unknown origin. Lancet, 1, 456.

Smith, J. J., and Furth, J. (1943). Fibrosis of the endocardium and the myocardium with mural thrombosis. Notes on its relationship to isolated (Fiedler's) myocarditis and to beriberi heart. Arch. intern. Med., 71, 602.

Still, W. J. S., and Boult, E. H. (1956). Pathogenesis of endocardial fibro-elastosis. Lancet, $2,117$.

$\longrightarrow$, and - (1957). The electron microscopy of endocardial fibroelastosis. Arch. Dis. Childh., 32, 298.

Stuart, K. L., and Hayes, J. A. (1963). A cardiac disorder of unknown etiology in Jamaica. Quart. f. Med., 32, 99.

Williams, A. W., Ball, J. D., and Davies, J. W. P. (1954). Endomyocardial fibrosis in Africa: its diagnosis, distribution and nature. Trans. roy. Soc. trop. Med. Hyg., 48, 290. 